6 OPEN ACCESS

${ }^{1}$ Department of Community Health and Epidemiology, Queen's University, Kingston, Ontario, Canada

${ }^{2}$ School of Kinesiology and Health Studies, Queen's University, Kingston, Ontario, Canada

${ }^{3}$ Department of Emergency Medicine, Queen's University, Kingston, Ontario, Canada

\section{Correspondence to} Dr William Pickett, Emergency Medicine Research, Queen's University, Clinical Research Centre, Angada 3, Kingston General Hospital, 76 Stuart St Kingston, ON K7L 2V7, Canada; will.pickett@queensu.ca

Accepted 20 April 2012 Published Online First 24 May 2012

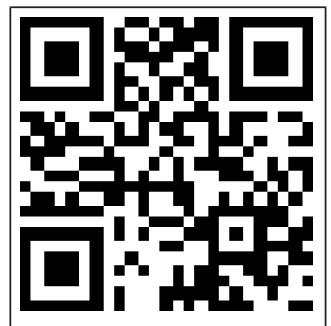

Scan to access more free content

\title{
Active transportation to school in Canadian youth: should injury be a concern?
}

\author{
Kathleen Gropp, ${ }^{1}$ Ian Janssen, ${ }^{1,2}$ William Pickett ${ }^{1,3}$
}

\begin{abstract}
Active transportation to school provides a means for youth to incorporate physical activity into their daily routines, and this has obvious benefits for child health. Studies of active transportation have rarely focused on the negative health effects in terms of injury. This crosssectional study is based on the 2009/10 Canadian Health Behaviour in School-Aged Children survey. A sample of children aged $11-15$ years $(n=20076)$ was studied. Multi-level logistic regression was used to examine associations between walking or bicycling to school and related injury. Regular active transportation to school at larger distances (approximately $>1.6 \mathrm{~km} ; 1.0$ miles) was associated with higher relative odds of active transportation injury (OR: $1.52 ; 95 \% \mathrm{Cl} 1.08$ to 2.15 ), with a suggestion of a dose-response relationship between longer travel distances and injury $(\mathrm{p}=0.02)$. Physical activity interventions for youth should encourage participation in active transportation to school, while also recognising the potential for unintentional injury.
\end{abstract}

Active transportation is the engagement in physical activity specifically for travel and includes activities such as walking and bicycling. ${ }^{1}$ This mode of transportation provides the means by which children and youth can incorporate physical activity into their daily routines. Indeed, children and youth who walk or bicycle to school have higher overall levels of physical activity, better cardiorespiratory fitness levels and a healthier body composition. ${ }^{23}$

Studies of active transportation in youth have focused on its positive contributions to the maintenance of a healthy body weight and overall physical activity (for a recent synopsis, see Lee et al); ${ }^{4}$ however, negative effects of active transportation are also possible. One concern is the occurrence of unintentional injury. Injury is the leading cause of death in Canadian children, accounting for more deaths than all other causes combined. ${ }^{5}$ Negative side effects of active transportation to school have not been thoroughly examined in populations of young people.

The objective of this brief report was therefore to evaluate regular active transportation to school and its effects on injury in a large and contemporary national sample of Canadian youth. No a priori hypotheses were assumed. The study base was the 2009/10 Health Behaviour in School-Aged Children study.

\section{METHODS}

\section{Overview of study design and measures}

Health Behaviour in School-Aged Children is a general health survey of preadolescent and adolescent children conducted in affiliation with
WHO. ${ }^{6}$ In Canada, Cycle 6 of this survey $(2009 / 10)$ involved administration of both student$(n=26078)$ and school-level administrator $(n=436)$ questionnaires. We combined these data with environmental measures describing school neighbourhoods that were obtained using geographic information systems.

\section{Participants}

The survey involved a systematic multi-stage cluster sample design that involved students and schools from 11 of 13 Canadian territories and provinces. ${ }^{6}$ The sample available for the current analysis was 19576 students with complete data (weighted sample 20076) from 419 schools. Implicit or explicit consent to participate was obtained from school boards, individual schools, parents/guardians and students, as per local jurisdictional requirements. The study protocol was approved by the General Research Ethics Board of Queen's University (study approval number: GEDUC-430-09).

\section{Key measures}

Based upon a standard self-report module, reports of active transportation injuries were identified for all participants for a 12-month period prior to survey administration. ${ }^{6}$ Injuries that required medical attention and which occurred: (1) in the 'street/road/parking lot' or while (2) 'biking/ cycling' or 'walking/running (not for a sports team or exercise)' were operationally defined as active transportation injuries.

Three levels of active transportation to school were identified: (1) youth who did not regularly engage in active transportation; (2) youth who regularly engaged and lived near their school; and (3) youth who regularly engaged but lived far from school. Participants who reported that their usual mode of transportation to school was 'bus, train, streetcar, subway, or boat/ferry' or 'car, motorcycle, or moped' were placed in category 1 . Students who reported regular active transportation (by walking or bicycling) with travel times either $<5 \mathrm{~min}$ for cycling or $<15 \mathrm{~min}$ for walking were placed in category 2 . Those reporting greater lengths of time for walking or bicycling were placed in category 3 . Participants who answered 'other' were excluded.

Both individual- and area-level variables were considered as potential confounders. Potential individual-level confounders were gender, age, ethnicity, perceived family socioeconomic status, perceived residential neighbourhood safety and participation in organised sports. Potential arealevel confounders describing the school neighbourhood were: urban/rural geographic status, average 
precipitation levels as reported by Environment Canada, summary measures of total road lengths, street or road connectivity, ${ }^{7}$ speed limits in the $1 \mathrm{~km}$ buffer surrounding each school, and Canada Census of Population estimates of median household incomes for 2006 (PCensus for MapPoint; Tetrad Computer Applications Inc., Vancouver, BC, Canada).

\section{Analysis}

Statistical analyses were performed using SAS V.9.2 (SAS Inc.). An initial descriptive analysis was used to characterise the study sample using proportions and measures of central tendency. Modelling was then performed. Examination of the clustered and nested structure of the data revealed an intraclass correlation of $2.6 \%(0.026)$ at the school-level. ${ }^{8}$ We therefore modelled effects at individual- and school-levels while accounting for this clustering. Multi-level logistic regression modelling was used with random intercepts permitted for each school. Standardised weights (mean $=1.00$ ) were calculated and applied to account for the fact that children from different provinces and territories, school board types, languages of instruction, and urban/rural geographic status had different probabilities of entering the sample.

Following bivariate analyses, multi-level models were built as follows: (1) the active transportation variable and all individuallevel factors were entered as risk factors (Multivariate Model 1); (2) backwards selection methods were performed using a change in estimate of $>10 \%$ for retention of individual-level variables ${ }^{9}$; then area-level variables were added to the retained individuallevel factors (Multivariate Model 2); and (3) backwards selection was reperformed for the final model, using the same change-inestimate approach (Multivariate Model 3). Conservatively, any covariate whose removal from the model caused a change in the estimate greater than $10 \%$ or was statistically significant $(p<0.05)$ was retained in Model 3. Finally, the modelling process was repeated for two specific active transportation injury outcomes: (1) walking or running injuries and (2) cycling injuries. A priori, the study was powered to identify an OR of 1.2 with $>80 \%$ power $(\alpha=0.05)$ for the main analysis.

\section{RESULTS}

A weighted sample of 20076 students from 419 schools with complete data was available for analysis. About a third (33.6\%) of the sample engaged in active transportation to school and 357 (1.8\% of the sample) incurred an active transportation injury (table 1). Of these injuries, $68.9 \%$ occurred while cycling, $31.1 \%$ occurred while walking or running, $45.1 \%$ required medical treatment (eg, placement of a cast or stitches) and $40.6 \%$ caused the participant to miss at least 1 day of school or usual extracurricular activities. Approximately one injury was reported for every $2900 \mathrm{~h}$ of exposure to active transportation.

Table 2 summarises bivariate, then adjusted models that describe the association between engagement in active transportation and the occurrence of related injury. ORs can be interpreted as relative risks. ${ }^{10}$ Model 3 provides final estimates for this relationship while controlling for potential confounders. A statistically significant positive association that followed a graded trend ( $p_{\text {trend }}=0.02$ ) was observed, with an adjusted 1.52 -fold increase ( $95 \%$ CI 1.08 to 2.15 ) in the relative odds of active transportation injury for youth who regularly engage in active transportation over longer distances. These effects were observed consistently for the two specific active transportation injury outcomes. Two covariates were retained in the final model: age group (OR: 0.75 ; 95\% CI 0.57 to 0.97 for ages $14-15$
Table 1 Description of sample demographics, engagement in active transportation and the occurrence of active transportation injuries $(\mathrm{N}=20076)$

\begin{tabular}{|c|c|c|c|c|}
\hline \multirow{2}{*}{$\begin{array}{l}\text { Demographic } \\
\text { characteristics }\end{array}$} & Weighted N & \multicolumn{2}{|c|}{$\begin{array}{l}\% \text { Engaged } \\
\text { in active } \\
\text { transportation }\end{array}$} & \multirow[t]{2}{*}{ p Value } \\
\hline & \multirow[b]{2}{*}{9531} & & & \\
\hline Male & & \multicolumn{2}{|l|}{36.4} & \multirow[t]{2}{*}{$<0.0001$} \\
\hline Female & 10545 & \multicolumn{2}{|l|}{31.0} & \\
\hline \multicolumn{5}{|l|}{ Age } \\
\hline $11-13$ & 11671 & \multicolumn{2}{|l|}{39.1} & \multirow[t]{2}{*}{$<0.0001$} \\
\hline $14-15$ & 8405 & \multicolumn{2}{|l|}{27.2} & \\
\hline \multicolumn{5}{|l|}{ Ethnicity } \\
\hline White only & 14315 & \multicolumn{2}{|l|}{31.1} & \\
\hline White and other & 974 & \multicolumn{2}{|l|}{36.6} & 0.95 \\
\hline Aboriginal & 1120 & \multicolumn{2}{|l|}{38.5} & 0.22 \\
\hline Other & 3667 & \multicolumn{2}{|l|}{40.8} & 0.004 \\
\hline \multicolumn{5}{|l|}{ Family socioeconomic status } \\
\hline Well-off 11 & 11490 & \multicolumn{2}{|l|}{32.5} & $<0.0001$ \\
\hline Average & 6771 & \multicolumn{2}{|l|}{34.1} & \\
\hline Not well-off & 1815 & \multicolumn{2}{|l|}{38.0} & \\
\hline Active transportation injuries & $\mathbf{N}$ & $\%$ of population & $\begin{array}{l}\% \text { of } \\
\text { trans }\end{array}$ & In injuries \\
\hline Total injuries & 357 & 1.8 & & \\
\hline Gender & & & & \\
\hline Male & 183 & 1.9 & & \\
\hline Female & 174 & 1.7 & & \\
\hline Age group & & & & \\
\hline $11-12$ & 234 & 2.0 & & \\
\hline $13-15$ & 123 & 1.5 & & \\
\hline Activity at time of injury & & & & \\
\hline Walking/running & 111 & & 31.1 & \\
\hline Cycling & 246 & & 68.9 & \\
\hline Required medical treatment & 161 & & 45.1 & \\
\hline Loss of $1+$ days of activity & 145 & & 40.6 & \\
\hline
\end{tabular}

vs $11-13$ ) and urban/rural status (OR: 1.64; 95\% CI 1.14 to 2.36 for urban vs rural communities; $p_{\text {trend }}=0.008$ ).

\section{DISCUSSION}

The most important finding from this study was that as young people engaged in active transportation for longer distances, their risks for active transportation injury increased irrespective of their mode of active transportation.

Many health promotion interventions aim to increase participation in active transportation to school due to its inherent benefits to health. ${ }^{11}$ However, these same interventions do not necessarily consider the negative outcomes of active transportation to school such as injury. Our findings therefore contribute to a more comprehensive understanding of this public health issue and associated health promotion messages.

This analysis has limitations. It is difficult to establish temporality in our observed effects due to the cross-sectional design. Our use of self-reported measures of injury and active transportation may have contributed to non-differential misclassification leading to bias of the ORs towards no effect. For example, it is quite possible that some of the events that were classified as active transportation injuries were actually recreational. Our lack of detailed information about some relevant contextual factors (eg, bicycle helmet laws, cycling infrastructure, pedestrian guards and crossings) are a further limitation, and the analysis also does not account for the timing of injuries and whether they were experienced outside of school commuting times. Finally, there is the possibility of selection 
Table 2 Results of multi-level logistic regression analysis examining potential risks for active transportation injury associated with engagement in active transportation to school $(\mathrm{N}=20076)$

\begin{tabular}{|c|c|c|c|c|c|c|}
\hline $\begin{array}{l}\text { Injury type: active } \\
\text { transportation level }\end{array}$ & $\mathbf{N}$ & $\%$ Injured & Bivariate model, OR $(95 \% \mathrm{CI})$ & Model 1*, OR (95\% Cl) & Model 2†, OR (95\% Cl) & Model 3‡, OR (95\% CI) \\
\hline \multicolumn{7}{|c|}{ Active transportation injuries } \\
\hline No & 13488 & 1.5 & 1.00 & 1.00 & 1.00 & 1.00 \\
\hline Yes: short distance & 5049 & 2.1 & $1.17(0.92$ to 1.50$)$ & $1.13(0.88$ to 1.45$)$ & $1.12(0.87$ to 1.44$)$ & $1.13(0.88$ to 1.44$)$ \\
\hline Yes: long distance & 1539 & 2.7 & $1.56(1.10$ to 2.21$)$ & $1.53(1.08$ to 2.17$)$ & $1.55(1.09$ to 2.20$)$ & 1.52 (1.08 to 2.15$)$ \\
\hline $\mathrm{p}$ Trend & & & 0.01 & 0.02 & 0.02 & 0.02 \\
\hline \multicolumn{7}{|l|}{ Walking/running injuries } \\
\hline No & 13488 & 0.4 & 1.00 & 1.00 & 1.00 & 1.00 \\
\hline Yes: short distance & 5049 & 0.8 & 1.54 (1.01 to 2.35$)$ & $1.59(1.04$ to 2.44$)$ & 1.52 (0.99 to 2.34$)$ & 1.49 (0.98 to 2.29$)$ \\
\hline Yes: long distance & 1539 & 0.8 & 1.47 (0.78 to 2.79$)$ & $1.52(0.80$ to 2.88$)$ & $1.44(0.76$ to 2.73$)$ & $1.43(0.76$ to 2.70$)$ \\
\hline p Trend & & & 0.06 & 0.05 & 0.08 & 0.08 \\
\hline \multicolumn{7}{|l|}{ Bicyling injuries } \\
\hline No & 13488 & 1.1 & 1.00 & 1.00 & 1.00 & 1.00 \\
\hline Yes: short distance & 5049 & 1.3 & $1.02(0.76$ to 1.39$)$ & $0.95(0.70$ to 1.29$)$ & $0.95(0.70$ to 1.31$)$ & $0.98(0.72$ to 1.33$)$ \\
\hline Yes: long distance & 1539 & 1.9 & 1.59 (1.05 to 2.40$)$ & $1.49(0.98$ to 2.25$)$ & 1.59 (1.05 to 2.41$)$ & $1.55(1.03$ to 2.35$)$ \\
\hline $\mathrm{p}$ Trend & & & 0.08 & 0.20 & 0.13 & 0.13 \\
\hline
\end{tabular}

*Adjusted for individual-level variables (gender, age, ethnicity, family socioeconomic status, perceived neighbourhood safety and participation in organised sports).

†Adjusted for retained individual-level variables (age) and area-level variables (urban/rural geographic status, street connectivity, speed limit surrounding school, \% roads with speed limit

$\leq 60 \mathrm{~km} / \mathrm{h}$, total length of roads, school neighbourhood median family income, total rain and total snow).

$\ddagger$ Adjusted for retained individual (age) and area-level (urban/rural geographic status) variables.

bias, such that youth not attending school on the day of survey administration may have been more likely to have active transportation injuries which in turn are differentially related to more active transportation to school. If this bias existed, it would again bias our OR estimates towards no effect.

The two main strengths of this research were our use of a large nationally representative sample of students as well as our focus on the negative side effects of an important public health topic with obvious benefits to health. Findings should be generalisable to urban populations in Canada and countries with like transportation infrastructures. Negative health outcomes of active transportation remain understudied in the adolescent health promotion literature, and there is a need for future

\section{What is already known on the subject}

Engagement in active transportation to school represents one possible strategy of promoting physical activity in groups of young people.

- While the positive effects of active transportation are obvious, possible negative effects of such practices in terms of unintentional injury have rarely been examined.

\section{What this study adds}

- This national study of young people from across Canada aimed to understand the effects of engagement in active transportation to school on the risks for related injury.

- Modest increases in risk for active transportation injury were evident, rising in accordance to distance travelled to school.

- Injury does represent one possible negative consequence of what in general is a positive behaviour for the health of young people. studies to evaluate the relative benefits (eg, reduced obesity) and potential harms (eg, increased injury) within the same analyses.

Public health interventions targeted at increasing active transportation to school in Canadian youth should consider possible unintentional injury outcomes of active transportation. Interventions aimed at increasing physical activity should not lose sight of possible injury-related outcomes. Examples of interventions include the walking school bus where children travel together in large groups ${ }^{12}$ and environmental solutions that foster improvements to walking and cycling infrastructure. ${ }^{13}$ If well designed, these population health interventions could have a very positive impact on the physical health of Canadian youth overall, while limiting the potential for associated injuries.

\section{CONCLUSION}

The relationship between active transportation to school and active transportation injury was examined in a nationally representative sample of Canadian youth using multi-level analytical methods. We found a dose-response relationship between active transportation to school and active transportation injury across increasing travel distances. We suggest that new and existing interventions promoting active transportation to school should further incorporate injury control strategies in order to continue encouraging physical activity in the safest possible manner.

Acknowledgements The authors would like to thank Andrei Rosu for the coordination of geographic information systems data collection. The principal investigators of the 2010 Canadian Health Behaviour in School-Aged Children study were William Pickett and John Freeman, and Matthew King was the national coordinator. The Health Behaviour in School-Aged Children study is coordinated internationally by Candace Currie (University of St. Andrews).

Contributors Each of the authors contributed to the conception of the study, its design, the analysis and interpretation of the data. KG drafted the article, with extensive critical revisions for intellectual content provided by WP and IJ. WP and IJ participated in the acquisition of the data. All authors have provided the final approval of the manuscript for publication. Each of the authors has met the listed criteria for authorship.

Funding HBSC is a WHO/European Region collaborative study and was funded in Canada by the Public Health Agency of Canada and Health Canada (Contract: 4500267124). This particular analysis was funded by an operating grant from the 
Canadian Institutes of Health Research (MOP 97962), and a second operating grant cofunded by the Canadian Institutes of Health Research and the Heart and Stroke Foundation of Canada (PCR 101415). KG was supported by the Empire Life Fellowship and the Ontario Neurotrauma Foundation. IJ was supported by a tier 2 Canada research chair.

\section{Competing interests None.}

Ethics approval Ethics approval was provided by the General Research Ethics Board, Queen's University and Health Sciences REB, Queen's University.

Provenance and peer review Not commissioned; externally peer reviewed.

Data sharing statement All data from this study are available from the authors upon request.

Open Access This is an Open Access article distributed in accordance with the Creative Commons Attribution Non Commercial (CC BY-NC 3.0) license, which permits others to distribute, remix, adapt, build upon this work non-commercially, and license their derivative works on different terms, provided the original work is properly cited and the use is non-commercial. See: http://creativecommons.org/licenses/by-nc/3.0/

\section{REFERENCES}

1. Sallis JF, Frank LD, Saelens BE, et al. Active transportation and physical activity: opportunities for collaboration on transportation and public health research. Transport Res A-Pol 2004;38:249-68

2. Dollman J, Lewis NR. Active transport to school as part of a broader habit of walking and cycling among South Australian youth. Pediatr Exerc Sci 2007;19:436-43.
3. Lubans DR, Boreham CA, Kelly P, et al. The relationship between active travel to school and health-related fitness in children and adolescents: a systematic review. Int J Behav Nutr Phys Act 2011;8. http://www.ijbnpa.org/content/8/1/5 (accessed 22 Dec 2011).

4. Lee MC, Orenstein MR, Richardson MJ. Systematic review of active commuting to school and childrens physical activity and weight. J Phys Act Health 2008:5:930-49.

5. Health Protection Branch, Health Canada. Canadian Injury Data. Ottawa, ON: Health Canada, 1999;11. http://publications.gc.ca/collections/Collection/H47-711999E.pdf (accessed 22 Dec 2011).

6. Griebler R, Molchol M, Samdal 0, et al. Health Behaviour in School-Aged Children (HBSC) Study Protocol: Background, Methodology and Mandatory Items for the 2009/ 10 Survey. Edinburgh: Child and Adolescent Health Research Unit; Vienna: Ludwig Boltzmann Institute of Health Promotion Research, 2010

7. Mecredy G, Janssen I, Pickett W. Neighbourhood street connectivity and injury in youth: a national study of built environments in Canada. Inj Prev 2012;18:81-7.

8. Snijders TAB, Bosker RJ. Multilevel Analysis: An Introduction to Basic and Advanced Multilevel Modeling. London: SAGE Publications, 1999:224-5.

9. Greenland S, Rothman KJ. Introduction to categorical statistics. In: Rothman KJ, Greenland S, Lash T, eds. Modern Epidemiology. 3rd edn. Philadelphia PA: Lippincott, Williams, and Wilkins, 2008:261-3.

10. Webb P, Bain C, Pirozzo S. Essential Epidemiology: An Introduction for Students and Health Professionals. Cambridge, UK: Cambridge University Press, 2005:108.

11. Chillon P, Evenson KR, Vaughn A, et al. A systematic review of interventions for promoting active transportation to school. Int J Behav Nutr Phys Act 2011;8. http:// www.ijbnpa.org/content/8/1/10 (accessed 22 Dec 2011).

12. Pedestrian and Bicycle Information Center. Starting a Walking School Bus. 2005. http://www.walkingschoolbus.org (accessed 22 Dec 2011).

13. Boarnet MG, Anderson CL, Day K, et al. Evaluation of the California Safe Routes to School Legislation: urban form changes and children's active transportation to school. Am J Prev Med 2005;28(Suppl 2):134-40.

\section{CMAJ calls for ski helmet regulation}

An editorial in the CMAJ calls for proper regulation of ski and snowboard helmets. It notes that 9\%-19\% of all ski or snowboard injuries involve the head but unlike hockey helmets, those for skiers are not required to meet Canadian Standard Association specifications. These standards are more rigorous than European or American standards.

Editor: Why Health Canada should have a fundamentally different view of the need for hockey helmets to conform to standards but not these helmets is truly a mystery.

\section{Another attempt to escape responsibility}

A minivan crashed into a school in rural Alberta injuring three children, one of whom died. The driver was charged with dangerous driving, resisting arrest and being in possession of a controlled substance (marijuana). The driver claims he was having a seizure. 